\title{
WMA to tackle adverse health conditions in prisons
}

Nigel Duncan Tel Aviv

Guidelines to combat the increasing public health problems in prisons are to be drawn up by the World Medical Association because of concern about, in particular, the rise of tuberculosis in eastern Europe.

At its annual general assembly last week in Tel Aviv, Israel, the association agreed to develop guidelines for doctors because it believed that adverse prison conditions across the world were leading to the spread of infection and risking the health of prisoners, prison visitors, prison staff, and medical staff.

The meeting heard of the crisis over the spread of tuberculosis among prisoners in the former Soviet Union, but also of problems elsewhere, including the development of hepatitis C in prisons in Australia and the continuing threat from HIV infection.
Dr James Appleyard, chairman of the association's working group on human rights, said: "These problems are the direct result of an abuse of human rights. They cannot be dealt with in conditions where there are overcrowded cells, no sunlight, no proper diet, and inadequate medical care."

He continued: "It is a crisis because these infections, including drug resistant organisms, are spreading outside the prisons. What we desperately want to see is a change in prison conditions, and our guidelines will include issues such as the need for medical screening in prison, availability of effective treatment, confidentiality, and the crucial independence of physicians."

Dr Appleyard said that the association would also be examining the healthcare plight of detainees: "In many parts of the world detainees are being denied the right to the same quality of health care as the rest of the population. Physicians looking after them also have the right to expect that they will have the same freedoms to offer care in the right way to their patients."

- The patenting of medical procedures poses serious risks to the effective practice of medicine by potentially limiting the availability of new procedures to patients, according to a new statement issued by the World Medical Association.

The statement declares that the patenting of medical procedures is unethical and contrary to the values of professionalism that should guide doctors' service to their patients and relations with their colleagues.

The statement makes a distinction between patenting medical devices, which it says is acceptable, and patenting medical procedures.

Nigel Duncan is press relations adviser to the World Medical Association.

\section{Antismoking campaigns should "target 4 year olds"}

Judy Jones Malmesbury, Wiltshire

Children as young as 4 years should be educated on the dangers of cigarettes if government targets to reverse the rise in smoking in children are to be met.

Many traditional methods of dissuading young people from taking up the habit have little or no effect, possibly because they do not start early enough, according to the NHS Centre for Reviews and Dissemination, University of York (Effective Health Care 1999;5(5)).

Existing programmes mostly target 11-17 year olds, by which time many young people have already established a regular smoking habit.

Full story in News Extra at www.bmj.com

\section{WHO celebrates triumph over river blindness}

James Ciment New York

The World Health Organisation this month celebrated a public health triumph-the virtual elimination of onchocerciasis, river blindness, in much of its west African home.

According to the WHO, the onchocerciasis control programme of west Africa has saved 100000 people at immediate risk of contracting the disease and prevented the potential infection of nearly 12 million children. In addition, 1.25 million people have lost their onchocercal infection through the programme.

But, added the WHO officials, preventing or controlling infection is only half the good news. Removing the threat of the disease, the agency said, has allowed people to farm 25 million hectares of fertile land capable of feeding 17 million people a year, that had been abandoned as a result of infestations of the black fly, the transmission vector of the disease.

The origins of the onchocerciasis control programme go back 25 years when the WHO joined with several other United Nations development agencies to launch a programme to eliminate the disease in seven west African countries.

But the real novelty of the programme, said the WHO officials, came several years later when a pioneering publicprivate partnership was struck

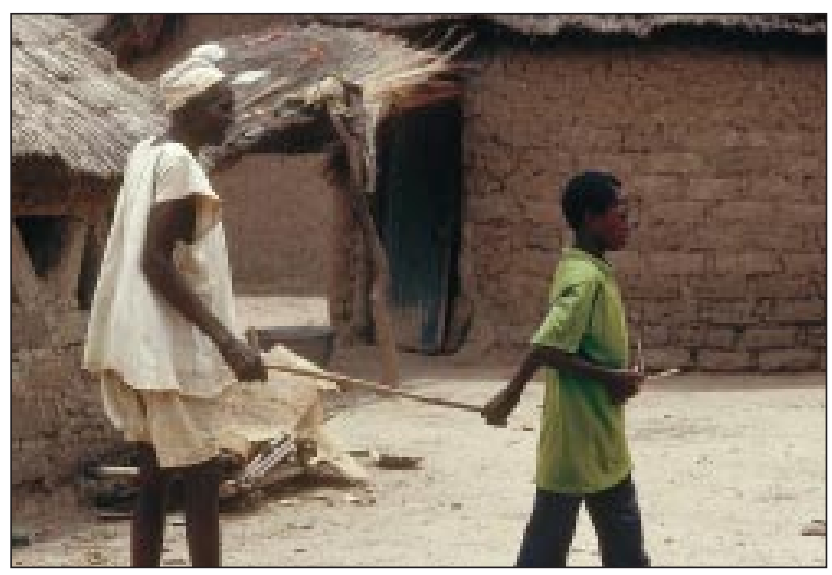

A boy is the "eyes" for his grandfather, a victim of onchocerciasis

between the UN agency consortium and Merck, the German pharmaceutical company that developed ivermectin (Mectizan) in the late 1980s. Ivermerctin represented a major breakthrough in the fight against river blindness, in that it was the first drug that could be dispensed widely without fear of serious side effects.

The programme, which is due to end in 2002, also included the training of west African nationals in public health and epidemiological surveillance.

\section{Scottish secretary of the BMA resigns}

\section{Annabel Ferriman BMJ}

The Scottish secretary of the BMA, Dr Brian Potter, has resigned from his post amid allegations that he had an affair with a male patient.

Dr Potter was a GP in Edinburgh from 1985 to 1992, when he became senior medical officer at the Scottish Office Home and Health Department.

In April 1995 Dr Potter took up the appointment of Scottish secretary to the BMA but resigned last week after several weeks off work. It is thought that Dr Potter, a divorcee with three children, has depression.

Dr Mac Armstrong, the secretary of the BMA, said that the decision has been accepted with regret. "Doctors throughout Scotland will acknowledge the debt he is owed for his work on behalf of the profession over many years," said Dr Armstrong. 